\title{
The HLA system and the arthropathies associated with psoriasis
}

\author{
C. J. EASTMOND, AND J. C. WOODROW \\ From the Nuffield Unit of Medical Genetics, Department of Medicine, University of Liverpool, \\ Ashton Street, Liverpool L69 3BX
}

SUMMARY Histocompatibility typing was carried out in 74 patients with psoriasis and an inflam matory arthropathy. In 40 patients with peripheral arthropathy characterized by distal interphalangeal joint involvement, $13(32.5 \%)$ were HLA-B27 positive, significantly higher than the contro! frequency $\left(\mathrm{P}=5.8 \times 10^{-6}\right) .26$ of the 40 patients did not have ankylosing spondylitis or radiologica $\vec{\hbar}$ sacroiliitis and 7 were HLA-B27 positive, also significantly higher than in controls $(P=0.0049)$.은 All 7 patients with psoriasis and ankylosing spondylitis without peripheral arthropathy wereHLA-B27 positive. The 10 patients with ankylosing spondylitis or radiological sacroiliitis who were HLA-B27 negative all had peripheral arthropathy.

It is suggested that being HLA-B27 positive increases the risk of a psoriatic patient developing $\overrightarrow{0}$ both peripheral arthropathy and ankylosing spondylitis. In addition, some of the genes involved in susceptibility to psoriasis also have a role in the pathogenesis of both types of arthropathy. AD hypothesis is put forward that some of the genes for psoriasis may be aetiologically important in some HLA-B27 negative patients with ankylosing spondylitis.

Following the reports of an association between the histocompatibility antigen HLA-B27 and ankylosing spondylitis by Brewerton et al. (1973) and Schlosstein et al. (1973) there have been a number of studies reporting on the frequency of this antigen in what Wright has termed the seronegative spondarthritides (Wright and Moll, 1973). Several studies of psoriatic arthropathy show general agreement that there is an association between HLA-B27 and psoriasis with ankylosing spondylitis with or without peripheral arthropathy (e.g. Brewerton et al., 1974; Karvonen, 1975). There is, however, no agreement concerning the frequency of this antigen in the absence of spinal involvement. Some workers have claimed an association (Brewerton et al., 1974; Karvonen, 1975), while others claim no association (Sany et al., 1975).

One of the problems with such a study is the definition of the clinical entity to be studied. Sany et al. (1975) included patients who were seropositive for rheumatoid factor, and the criteria used by Metzger et al. (1975) for radiological spondylitis could have included patients with and without sacroiliitis. Moll and Wright (1973a) identified four types of peripheral arthropathy related to psoriasis.

Accepted for publication June 16, 1976 Correspondence to Dr. J. C. Woodrow
They were (1) a polyarthritis characterized by distale interphalangeal joint involvement, (2) mutilans 3 arthritis with telescoping digits, (3) a symmetrical seronegative polyarthritis, and (4) an asymmetrica? oligoarthritis including 'sausage digits'. Because of the heterogeneity of the clinical picture in psoriatic arthropathy we decided to HLA type all patients 3 referred to us who had psoriasis with an inflammatory peripheral arthritis and to categorize them subse- 3 quently independent of the knowledge of their HLA응 type. We also studied a group of patients who have ankylosing spondylitis with or without peripherato arthropathy.

\section{Patients}

The patients either were attending our own clinic or were referred to us by colleagues for study. All were examined by one or both of us. Patients with peripheral arthropathy involving the hands and feet had? radiographs of these joints and in addition anteroposterior and lateral radiographs of the spine, a posteroanterior view of the sacroiliac joints, and an $\mathbb{D}$ anteroposterior view of the pelvis. Spinal, sacroiliac, $\stackrel{\mathbb{\mathbb { D }}}{\overrightarrow{\mathrm{C}}}$ and pelvic radiographs were not done in females $\triangle$ under the age of 45 years who did not have back symptoms. 
Table 1 Number of patients with psoriatic arthropathy in each clinical group

\begin{tabular}{|c|c|c|c|c|c|c|c|c|c|c|}
\hline \multirow[t]{2}{*}{ Clinical groups } & \multicolumn{2}{|c|}{$\begin{array}{l}\text { Peripheral joint } \\
\text { disease alone }\end{array}$} & \multicolumn{2}{|c|}{ With sacroiliitis } & \multicolumn{2}{|c|}{$\begin{array}{l}\text { With spondylitis } \\
\text { without sacroiliitis }\end{array}$} & \multicolumn{2}{|c|}{$\begin{array}{l}\text { Sacroiliitis not } \\
\text { known }\end{array}$} & \multicolumn{2}{|c|}{ Total no. } \\
\hline & $M$ & $\boldsymbol{F}$ & $M$ & $F$ & $M$ & $F$ & $\boldsymbol{M}$ & $F$ & $M$ & $\boldsymbol{F}$ \\
\hline \multicolumn{11}{|l|}{ Peripheral arthritis } \\
\hline Group 1 & 11 & 12 & 6 & 3 & 3 & - & - & 5 & 20 & 20 \\
\hline Groups 2,3 , and 4 & - & 3 & 3 & 5 & - & 1 & - & - & 3 & 9 \\
\hline Group 5 & 1 & - & 4 & - & - & - & 1 & 1 & 6 & 1 \\
\hline Group 6 (a) seropositive & 1 & 3 & - & - & - & - & - & - & 1 & 3 \\
\hline $\begin{array}{l}\text { (b) seronegative } \\
\text { Spondylitis }\end{array}$ & 1 & 1 & - & - & - & - & - & - & 1 & 1 \\
\hline Ankylosing spondylitis & - & - & 6 & 1 & - & - & - & - & 6 & 1 \\
\hline $\begin{array}{l}\text { Spondylitis without } \\
\text { sacroiliitis }\end{array}$ & - & - & - & - & 2 & - & - & - & 2 & - \\
\hline Total & 14 & 19 & 19 & 9 & 5 & 1 & 1 & 6 & 39 & 35 \\
\hline
\end{tabular}

\section{PERIPHERAL ARTHROPATHY}

Of the patients with peripheral arthropathy and psoriasis seen during this study we have been able to identify the following groups (Table 1).

\section{Group 1}

Forty patients with peripheral arthropathy characterized by distal interphalangeal involvement alone or as part of a polyarthritis (DIP disease).

\section{Group 2}

Nine patients with a polyarthritis differing clinically from rheumatoid arthritis but not having definite DIP joint involvement. These patients are tabulated individually (Table 2).

\section{Group 3}

Two patients with a polyarthritis clinically indistinguishable from rheumatoid arthritis but with unusual radiological features (Table 2 ).

\section{Group 4}

One patient with arthritis mutilans, i.e. telescoping digits (Table 2).

\section{Group 5}

Seven patients with a monarthritis (in all cases a synovitis of the knee joint).

\section{Group 6}

Six patients with a polyarthritis clinically and radiologically indistinguishable from rheumatoid arthritis.

The patients in groups 2,3 , and 4 probably represent a heterogeneous group and it is for this reason that they have been tabulated individually. Sausage digits are probably the result of combined proximal and DIP joint involvement together with a flexor sheath tendonitis. Although DIP involvement is therefore implied, patients with sausage digits have not been included in group 1 unless DIP involvement

Table 2 Details of patients in groups 2, 3, and 4

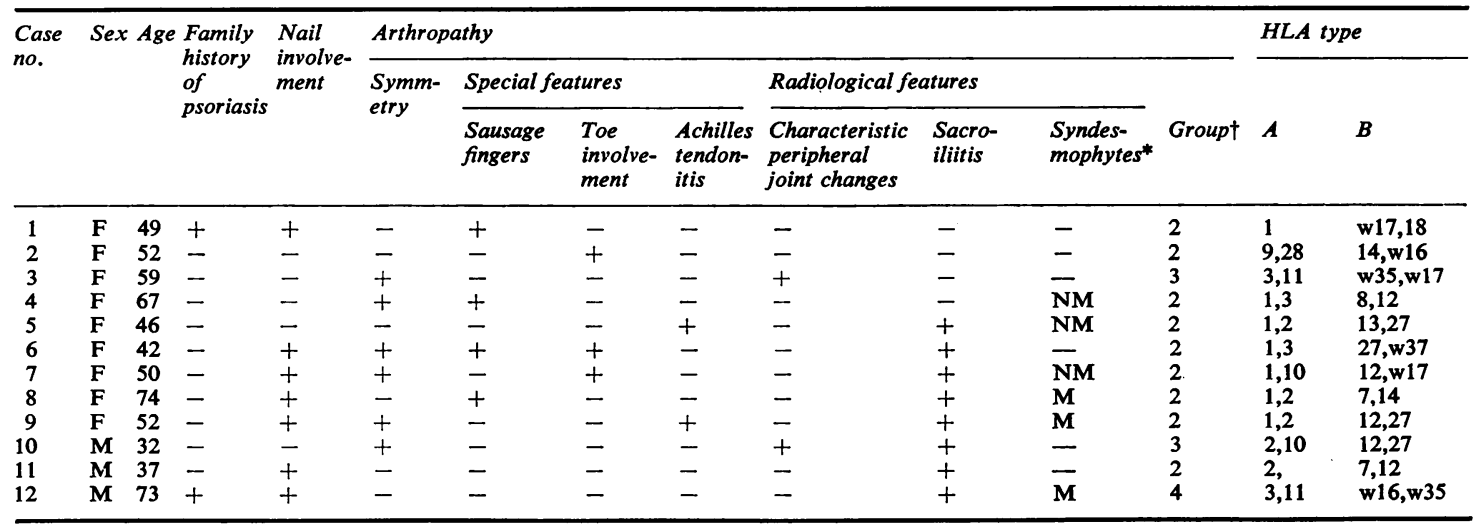

*M $=$ marginal syndesmophytes $; \mathbf{N M}=$ nonmarginal syndesmophytes.

† See text. 


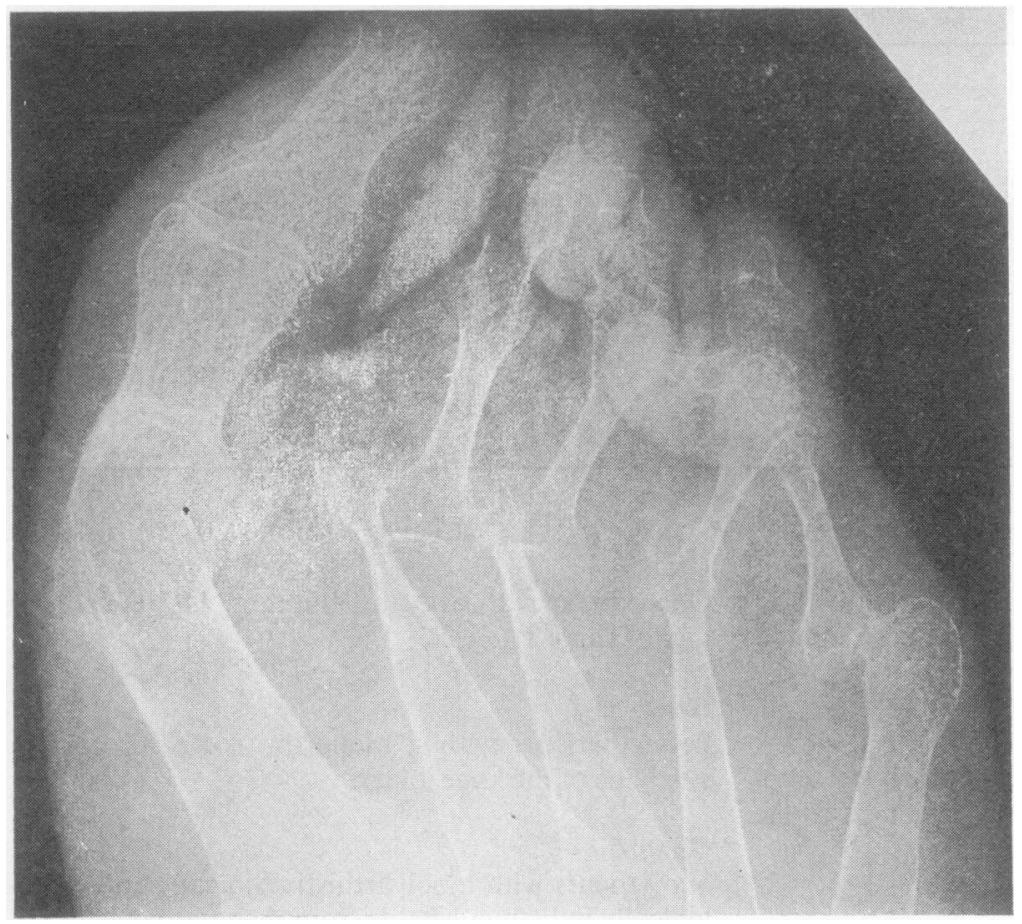

Fig. 1 Radiograph of foot of Case 3 (group 3) showing whittling of the distal ends of the metatarsals.

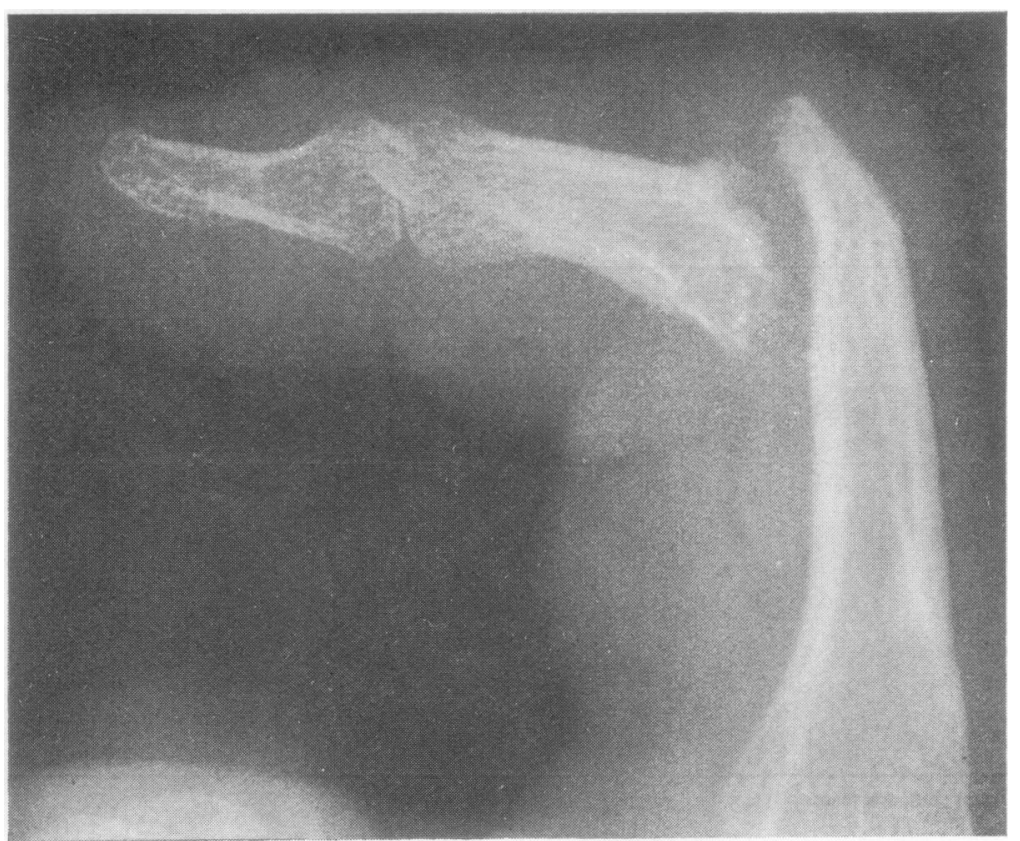

Fig 2 Radiograph of the index ex finger of Case 10 (group 3) showing destructive arthritis of or the proximal interphalangeal joint with whittling of the distal end of the proximal phalanx. 
has also occurred as a discrete event. In 2 of the patients in this group Achilles tendonitis was a feature and although it has been suggested that it occurs in rheumatoid arthritis (Bywaters, 1954) it is probably more characteristic of the seronegative spondarthritides. The radiographs of the 2 patients in group 3 are shown in Figs. 1 and 2. Case 10 is of interest because his peripheral arthropathy started at the age of 10 years, the symptoms of ankylosing spondylitis at age 19 years, whereas psoriasis did not appear until he was 29 years old.

With regards to group 6 , synovitis of the knee is a relatively nondiagnostic finding, occurring in a variety of inflammatory rheumatic disorders. Hence its occurrence in a patient with psoriasis does not necessarily mean that the monarthritis is in any way related to the presence of psoriasis, though it may be. The problem of categorizing these patients is typified

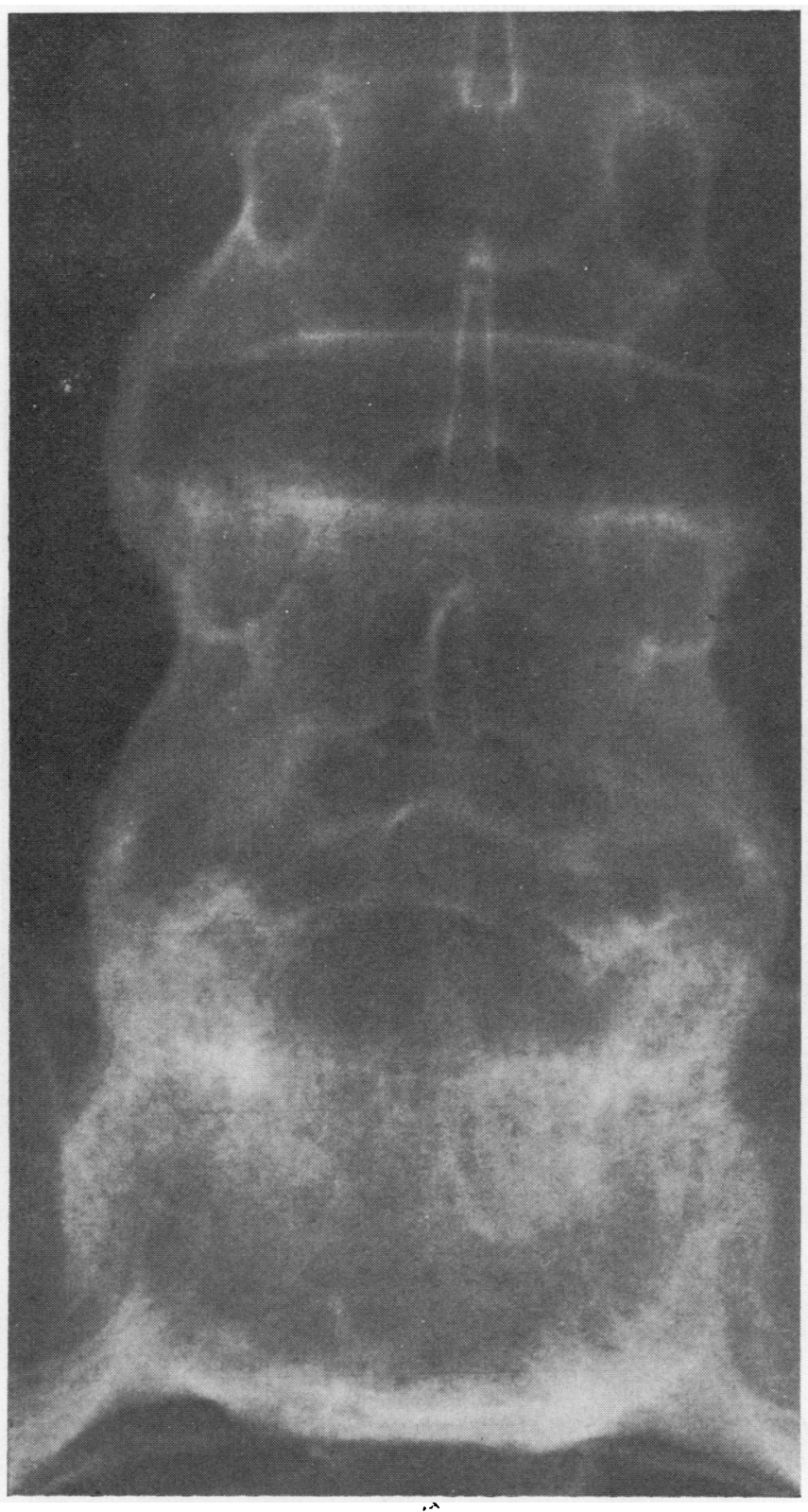

Fig. 3 Anteroposterior radiograph of the lower lumbar spine of a patient with spondylitis without sacroilitis showing nonmarginal syndesmophytes at L3,4,5 level laterally. 
by such a patient who has subsequently developed typical nail dystrophy and DIP disease, and has now been included in this latter category. Similarly, patients who may subsequently develop ankylosing spondylitis may originally present with a monarthritis, frequently of the knee, or this may occur after the development of spinal disease. It is for these reasons that we have analysed our data on patients with a monarthritis of the knee separately from the other groups of peripheral arthropathy. 4 of the 6 patients in group 6 were seropositive for rheumatoid factor.

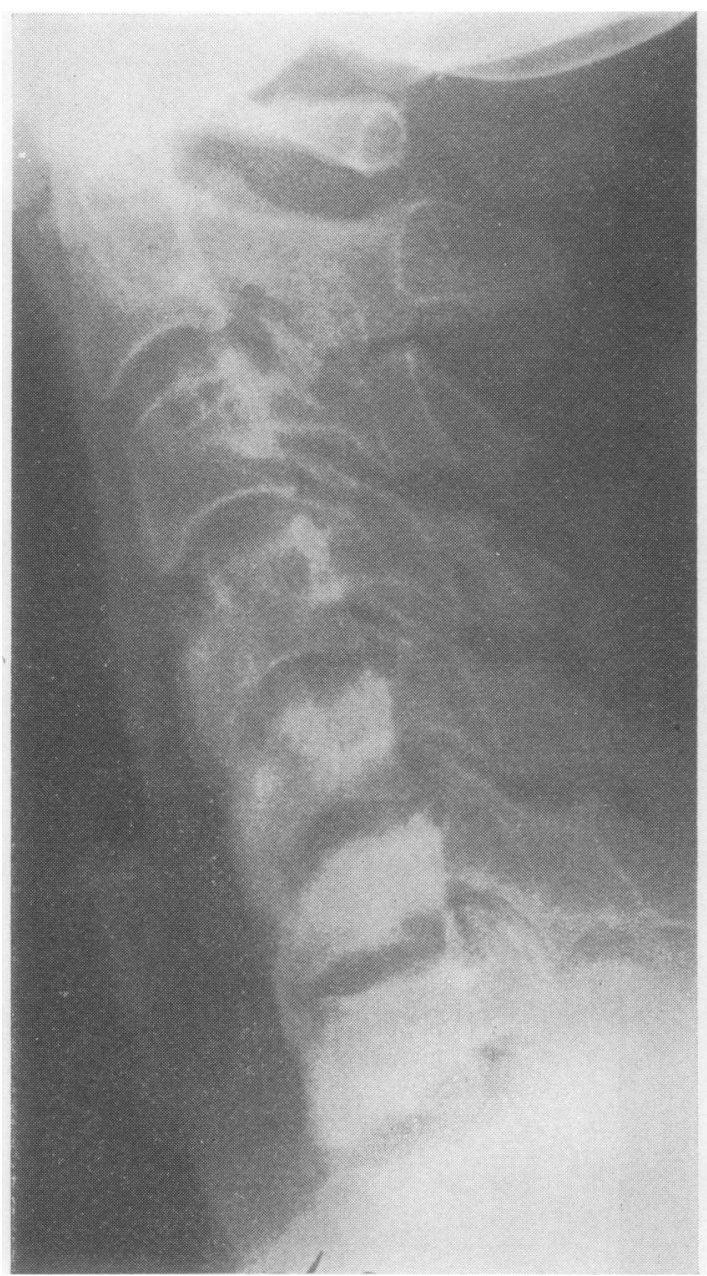

Fig. 4 Lateral radiograph of the cervical spine of the same patient illustrated in Fig. 3 to show florid nonmarginal syndesmophytes anteriorly.
SPONDYLITIS

Ankylosing spondylitis

In addition to the patients with peripheral arthro- $\stackrel{5}{\circ}$ pathy, we also studied a group of 7 patients with? ankylosing spondylitis without peripheral arthro-흘 pathy (Table 1). Of the 28 patients with ankylosing $\frac{\text { के }}{7}$ spondylitis with and without peripheral arthropathy $\varrho$ 14 had sacroiliitis alone, 8 marginal syndesmophytes, and 6 nonmarginal syndesmophytes.

\section{Spondylitis without sacroiliitis}

Six patients ( 5 male, 1 female) were seen who had

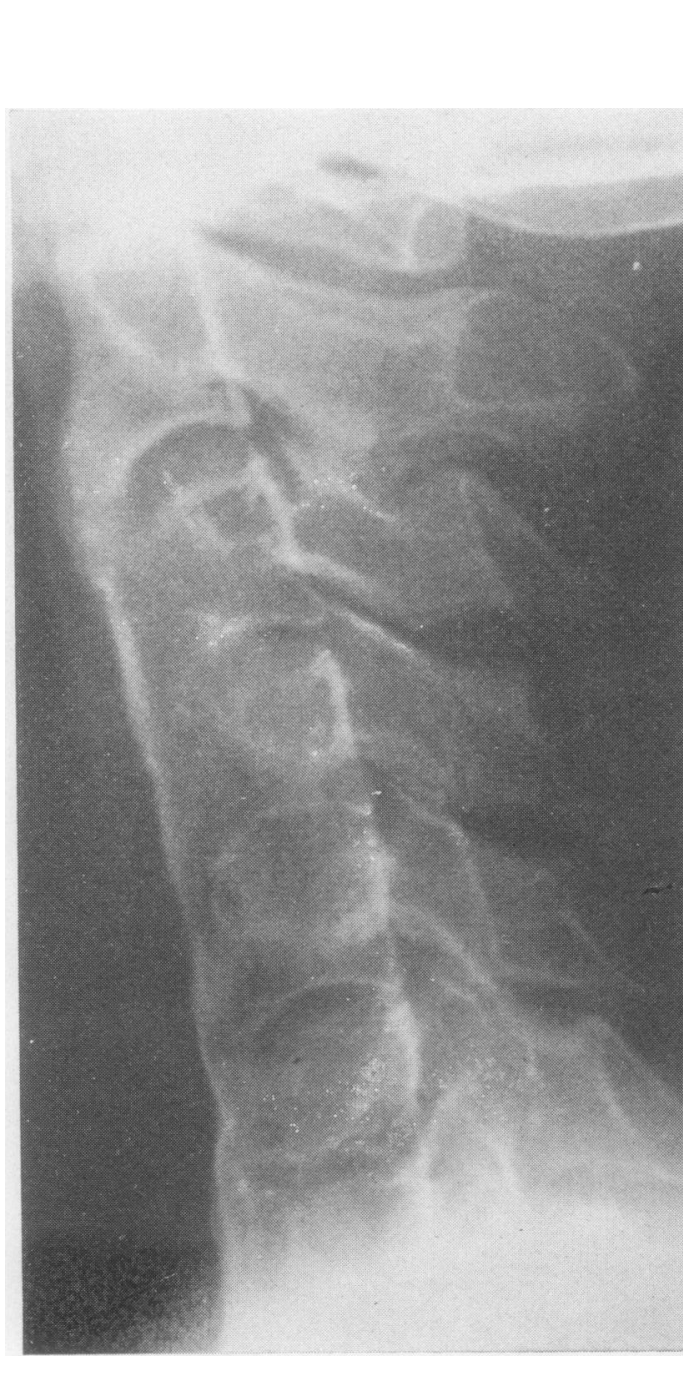

Fig. 5 Lateral radiograph of the cervical spine of the same patient as illustrated in Fig. 4, 3 years later. 
radiological changes in the spine not conforming to ordinary degenerative changes and who did not have sacroiliitis (Table 1). 3 of the 6 had DIP disease and are included in group 1 and one of these had changes similar to ankylosing vertebral hyperostosis. Another patient with similar radiological changes did not have peripheral joint disease, but complained of backache and stiffness. A further patient who also had DIP disease had changes on the right side of the lower dorsal spine similar to ankylosing hyperostosis but anteriorly the changes were more typical of nonmarginal syndesmophytes. One other patient with DIP disease had a nonmarginal syndesmophyte anteriorly at the D12-L1 level. Another male patient with psoriasis who had no peripheral joint disease but complained of back pain and stiffness at the age of 35 years has now at the age of 47 years nonmarginal syndesmophytes bridging the $\mathrm{L} 3,4,5$ disc spaces laterally (Fig. 3) and the L3,4,5 spaces anteriorly. Over this period he has also developed nonmarginal syndesmophytes anteriorly throughout the cervical spine (Fig. 4) which have subsequently developed into a layer of new bone anterior to the cervical vertebrae (Fig. 5). The dorsal and upper lumbar spine are unaffected. The one female in this group is also in group 2. She has nonmarginal syndesmophyte formation at the C5,6,7 level, associated with pain in the neck.

\section{FAMILY STUDIES}

Each patient was asked if a first- or second-degree relative had psoriasis. Selected families, where it was known that a relative had a seronegative arthropathy, were studied.

\section{Histocompatibility typing}

Histocompatibility typing was performed on all patients using a two-stage lymphocytotoxicity micromethod (Terasaki and McLelland, 1964), Control blood samples were obtained from 433 blood donors and members of staff.

\section{Results}

\section{ASSOCiation With hLA-B27 (TABle 3) \\ Peripheral arthropathy}

Group 113 of the 40 patients $(32.5 \%)$ had HLAB27 compared with 36 of our 433 controls (8.31\%), giving $\chi_{c}^{2}=20.54 ; P=5.8 \times 10^{-6} .26$ of the 35 patients who had pelvic radiographs had normal sacroiliac joints. 7 of these had HLA-B27 and compared with controls, $\chi^{2} \mathrm{c}=7.93 ; \mathrm{P}=0.0049$. 9 patients had radiological sacroiliitis and $5(55 \cdot 6 \%)$ of these were HLA-B27 positive. Comparison with controls gives $\chi_{c}^{2}=18.1 ; P=2.1 \times 10^{-5}$. Of the 5 female patients who did not have sacroiliac radiographs, one was HLA-B27 positive.

Groups 2, 3, 4 Table 2 gives the clinical and radiological features and HLA phenotypes of the patients in these groups. It can be seen that all 3 male

Table 3 Frequencies of $H L A-B 27$ and $B w 17$ in patients with psoriatic arthropathy, in patients with psoriasis, and in controls

\begin{tabular}{|c|c|c|c|c|c|}
\hline \multirow[t]{2}{*}{ Clinical groups } & \multirow{2}{*}{$\begin{array}{l}\text { No. of } \\
\text { patients }\end{array}$} & \multicolumn{2}{|c|}{ HLA-B27 positive } & \multicolumn{2}{|c|}{ HLA-BwI7 positive } \\
\hline & & No. & $\%$ & No. & $\%$ \\
\hline \multicolumn{6}{|l|}{ (A) Peripheral arthritis } \\
\hline Group 1 & 40 & 13 & $32 \cdot 5$ & 12 & $30 \cdot 0$ \\
\hline DIP disease alone & 26 & 7 & 30.4 & 9 & $34 \cdot 6$ \\
\hline , + sacroiliitis & 9 & 5 & 55.6 & 1 & $11 \cdot 1$ \\
\hline Groups 2,3 , and 4 & 12 & 4 & $33 \cdot 3$ & 3 & $25 \cdot 0$ \\
\hline Peripheral arthritis alone & 4 & $\mathbf{0}$ & 0 & 2 & $50 \cdot 0$ \\
\hline , $\quad+$ sacroiliitis & 8 & 4 & $50 \cdot 0$ & 1 & $12 \cdot 5$ \\
\hline Group 5 & 7 & 2 & $28 \cdot 6$ & 1 & $14 \cdot 3$ \\
\hline Peripheral arthritis alone & 3 & $\mathbf{0}$ & $\mathbf{0}$ & 1 & $33 \cdot 3$ \\
\hline , + sacroiliitis & 4 & 2 & $50 \cdot 0$ & 0 & 0 \\
\hline \multicolumn{6}{|l|}{ Group 6} \\
\hline Seropositive RA & 4 & 1 & $25 \cdot 0$ & 2 & $50 \cdot 0$ \\
\hline Seronegative RA & 2 & 1 & $50 \cdot 0$ & $\mathbf{0}$ & 0 \\
\hline \multicolumn{6}{|l|}{ (B) Spinal disease } \\
\hline Ankylosing spondylitis (all) & 28 & 18 & $64 \cdot 3$ & 2 & $7 \cdot 1$ \\
\hline peripheral arthropathy & 7 & 7 & $100 \cdot 0$ & $\mathbf{0}$ & 0 \\
\hline Spondylitis without sacroiliitis & 6 & 0 & 0 & 2 & $33 \cdot 3$ \\
\hline (C) Liverpool Psoriasis Series & & & & & \\
\hline (Woodrow and others (1975)) & 125 & 15 & $12 \cdot 0$ & 63 & $50 \cdot 4$ \\
\hline (D) Controls & 433 & 36 & $8 \cdot 3$ & 34 & $7 \cdot 9$ \\
\hline
\end{tabular}


and 5 of the 9 female patients had radiological sacroiliitis and HLA-B27 was present in 4 of these 8 $(50 \%)$, but did not occur in the 4 female patients without sacroiliitis.

Group 5 Of the 7 patients with a synovitis of the knee, 4, all male, had ankylosing spondylitis and 2 $(50 \%)$ were HLA-B27 positive. The remaining 3 patients, 2 of whom were male, did not have this antigen.

Group 6 Of the 4 patients with seropositive rheumatoid arthritis, one had HLA-B27. Of the 2 seronegative patients in this group, one had HLA-B27.

\section{Spondylitis}

Ankylosing spondylitis Of the total of 28 patients (19 males, 9 females) with ankylosing spondylitis or radiological sacroiliitis, HLA-B27 was present in $18(64.3 \%)$, and comparison with controls gives $\chi^{2} \mathrm{c}=74.35 ; \mathrm{P}=6.5 \times 10^{-18}$. All 7 patients who had ankylosing spondylitis in association with psoriasis in the absence of any peripheral joint involvement were HLA-B27 positive. 6 of these were male and all had an age of onset of their back symptoms before the age of 40 years. In contrast, of the 21 patients who in addition had various forms of peripheral arthropathy, only 13 were male and of the 16 in whom it was possible to ascertain the age of onset of back symptoms with reasonable accuracy, 7 had at onset after the age of 40 years. 11 of these 21 patient were HLA-B27 positive, a frequency significant less than the $90 \%$ found in a personal series of $11 \overline{8}$ patients with ankylosing spondylitis without psorias $\operatorname{sis}\left(\chi_{c}^{2}=15.67 ; P=7.5 \times 10^{-5}\right)$.

Of the 10 patients with sacroiliitis who were B2y negative all had peripheral joint involvement; 4 if group 1, 3 in group 2, the one in group 4, and 2 in group 5. HLA-B27 was present in 8 of the 14 patients with radiological sacroiliitis only, in 5 of the 8 patients with marginal syndesmophytes, and in 3 of the 6 with nonmarginal syndesmophytes. There were no significant differences between these groups in the frequency of HLA-B27.

Spondylitis without sacroiliitis None of the patients with spondylitis in the absence of sacroiliitis were HLA-B27 positive.

\section{OTHER HLA ANTIGENS}

Because of the known association of psoriasis with HLA-Bw17 and B13 (White et al., 1972), the frequencies of these two antigens in our patien with psoriatic arthropathy were also studied. The results for HLA-Bw17 are summarized in Table \& There was a significant increase in the frequency

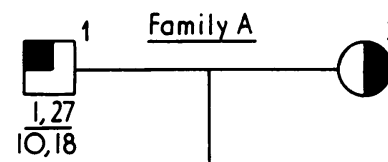

II

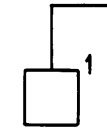

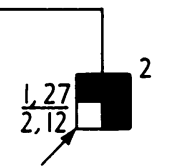

I $A 2,11 ; B 8,27$
Fomily B

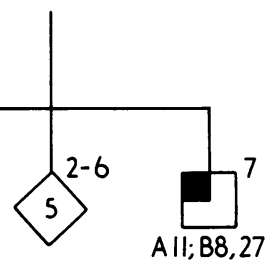

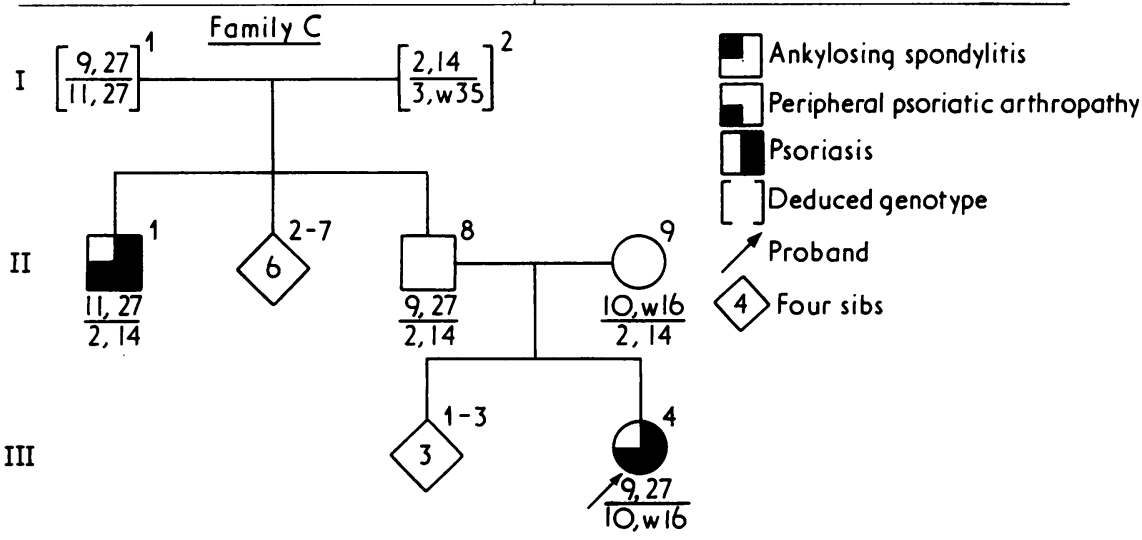

Fig. 6 Pedigrees of families $A, B$, and $\mathbb{Q}$ 
this antigen in patients with peripheral arthropathy but not in those with ankylosing spondylitis.

Four patients were HLA-B13 positive. 3 of these had radiological sacroiliitis and were also HLA-B27 positive. The overall frequency of HLA-B13 in patients with sacroiliitis was $10.7 \%$. One of these 3 patients had group 1 peripheral arthropathy, one (Case 5) had group 2 peripheral arthropathy, and one had no peripheral arthropathy. The fourth HLA-B13 positive patient had group 1 peripheral arthropathy and was also HLA-Bw17 positive. The frequency of HLA-B13 in peripheral arthropathy was $5 \%$, compared with $5.3 \%$ or healthy controls, and with $9.6 \%$ in unselected psoriatic patients in Liverpool (Woodrow et al., 1975).

\section{FAMILY STUDIES}

A positive family history of psoriasis was obtained in 25 of the $75(33.3 \%)$ patients with psoriasis and arthropathy and this is not significantly different from the frequency of $40.1 \%$ found in a general series of 157 psoriatic patients (Woodrow et al., 1975). Three families are shown in Fig. 6. Family A shows an HLA-B27 positive proband who has ankylosing spondylitis and psoriasis, whose HLAB27 positive father has ankylosing spondylitis with no psoriasis and whose mother has only psoriasis.

In Family B the brother of one of the HLA-B27 positive female patients (Case 9) with ankylosing spondylitis and group 2 peripheral arthropathy had himself ankylosing spondylitis without psoriasis and was HLA-B27 positive. Family $C$ is of particular interest in that the proband and her paternal uncle both had group 1 peripheral arthropathy (DIP disease) and psoriasis. Both had a genotype including HLA-B27 but the haplotypes were different. The father of the proband had neither ankylosing spondylitis nor psoriasis.

\section{Discussion}

The results of this study show that there is a significant increase in the frequency of HLA-B27 in patients with DIP disease whether or not radiological sacroiliitis is present. This suggests that being HLAB27 positive increases the risk of a psoriatic patient developing this type of arthropathy. In respect of the other types of peripheral arthropathy, although overall there is an increase in the frequency of HLAB27, the fact that most of the patients also had ankylosing spondylitis or radiological sacroiliitis, and the small numbers in each group make it impossible to determine whether or not HLA-B27 is associated with an increased risk of developing these forms of arthropathy.
Among the 28 patients with ankylosing spondylitis or radiological sacroiliitis were 7 who had no peripheral arthropathy. It is reasonable to expect that ankylosing spondylitis will occur as frequently in patients with psoriasis as in people without psoriasis simply by chance, and these 7 patients could represent such an occurrence. In support of this is the finding that all were HLA-B27 positive, all but one were male, and all had onset of back symptoms before the age of 40 years. This pattern is characteristic of any group of patients having ankylosing spondylitis in the absence of psoriasis. In Moll and Wright's (1973b) family study of 88 probands with psoriatic arthropathy there were 6 with ankylosing spondylitis and no peripheral arthropathy of whom only one was female.

In contrast the remaining 21 patients, all of whom had peripheral arthropathy in addition to ankylosing spondylitis or radiological sacroiliitis, also differed from the 7 patients without peripheral arthropathy in having a higher proportion of females, a tendency to a later age of onset of back symptoms and much lower frequency of HLA-B27. The frequency of HLA-B27 in this group is significantly less than that found in our own series of 116 patients with ankylosing spondylitis alone. These differences between the two groups of patients with psoriasis and ankylosing spondylitis or radiological sacroiliitis can be interpreted as suggesting that in the complex of genes predisposing to psoriasis are particular genes that cause susceptibility to both peripheral arthropathy and ankylosing spondylitis in the absence of HLA-B27.

Among 12 HLA-B27 negative patients in a series of 116 patients with ankylosing spondylitis without psoriasis, 3 had an inflammatory peripheral small joint arthropathy with clinical or radiological features identical with those seen in patients with peripheral psoriatic arthropathy. It seems possible, therefore, that genes for psoriasis may also play a role in the pathogenesis of some HLA-B27 negative patients with ankylosing spondylitis who do not have psoriasis. This hypothesis is illustrated in Table 4. It might also be speculated that these same genes for psoriasis might also result in the seronegative peripheral arthropathies without psoriasis seen by Moll and Wright (1973b) in the families of probands with psoriatic arthropathy.

Family A (Fig. 6) could be interpreted as representing the chance coincidence of HLA-B27 positive ankylosing spondylitis and psoriasis in the proband; his father having HLA-B27 positive ankylosing spondylitis alone, and his mother psoriasis alone. Family B (Fig. 6) may be interpreted in two ways. First, it could be that the proband's brother without psoriasis has HLA-B27 positive ankylosing spondy- 
Table 4 Interpretation of the contributing genes in psoriatic arthropathy and some patients with $H L A-B 27$ negative ankylosing spondylitis

\begin{tabular}{llll}
\hline & & \multicolumn{2}{c}{$\begin{array}{c}\text { Genes predisposing to } \\
\text { arthropathy }\end{array}$} \\
\cline { 2 - 4 } & Type of arthropathy & $\begin{array}{l}\text { Psoriasis } \\
\text { genes }\end{array}$ & HLA-B27 \\
\hline $\begin{array}{c}\text { Patients with } \\
\text { psoriasis }\end{array}$ & $\begin{array}{c}\text { Peripheral } \\
\text { arthropathy alone } \\
\text { Peripheral } \\
\text { arthropathy with } \\
\text { sacroiliitis } \\
\text { Ankylosing } \\
\text { spondylitis alone }\end{array}$ & + & + \\
Patients without \\
psoriasis & $\begin{array}{c}\text { HL-B27 negative } \\
\text { ankylosing } \\
\text { spondylitis }\end{array}$ & + & + \\
\hline
\end{tabular}

litis, the proband having in addition genes for psoriasis predisposing to peripheral arthropathy. The second possibility is that HLA-B27 in the proband has increased her susceptibility to both peripheral arthropathy and ankylosing spondylitis in the presence of genes for psoriasis, whereas in her brother, in the absence of these genes, susceptibility was only increased for ankylosing spondylitis. Family C (Fig. 6) suggests that genes for psoriasis have interacted with two independently inherited HLA-B27 genes to predispose to DIP disease in 2 individuals.

Overall the frequencies of HLA-Bw17 and B13 are not significantly different from those found in a group of psoriatic patients not selected for arthropathy (Woodrow et al., 1975), once allowance has been made for the increased frequency of HLA-B27 in those with arthropathy.

We are grateful to our colleagues who allowed us to study their patients. We are indebted to the National Tissue Typing Reference Laboratory, Bristol, and to the Transplantation and Immunology Branch,
National Institutes of Health, Bethesda, Marylanç for supplying typing sera.

C. J. E. received financial support from the Medical Research Committee of the Mersey Regiona Health Authority. Mr. N. Usher and others provide excellent technical assistance.

\section{References}

Brewerton, D. A., Caffrey, M., Hart, F. D., James, D. C. OP्? Nicholls, A., and Sturrock, R. D. (1973). Ankylosin $\overrightarrow{\mathbf{g}_{\text {t }}}$ spondylitis and HLA 27. Lancet, 1, 904-907.

Brewerton, D. A., Caffrey, M., Nicholls, A., Walters, D., an\& James, D. C. O. (1974). HLA 27 and arthropathies asso ciated with ulcerative colitis and psoriasis. Lancet, 956-958.

Bywaters, E. G. L. (1954). Heel lesions of rheumatoid arthrio tis. Annals of the Rheumatic Diseases, 13, 42-51.

Karvonen, J. (1975). HL-A antigens in psoriasis with speciab reference to the clinical type, age of onset, exacerbations after respiratory infections and occurrence of arthritis. Annals of Clinical Research, 7, 301-311.

Metzger, A. L., Morris, R. I., Bluestone, R., and Terasak P. I. (1975). HL-A W27 in psoriatic arthropathy. Arthrit and Rheumatism, 18, 111-115. Moll, J. M. H., and Wright, V. (1973a). Psoriatic arthritis.
Seminars in Arthritis and Rheumatism, 3, 55-78.

Moll, J. M. H., and Wright, V. (1973b). Familial occurrence of psoriatic arthritis. Annals of the Rheumatic Diseases, 32 181-201.

Sany, J., Seignalet, J., Guilhou, J.-J., and Serre, H. (1975 HL-A et rhumatisme psoriasique. Revue du Rhumatisme \& des Maladies Ostéo-articulaires, 42, 451-460.

Schlosstein, L., Terasaki, P. I., Bluestone, R., and Pearsol? C. M. (1973). High association of an HL-A antigen, W2 $\vec{b}$ with ankylosing spondylitis. New England Journal $\mathcal{\mathcal { A }}$ Medicine, 288, 704-706.

Terasaki, P. I., and McClelland, J. D. (1964). Microdroplef assay of human serum cytotoxins. Nature, 204, 998-1000.

White, S. H., Newcomer, V. D., Mickey, M. R., and Terasakg P. I. (1972). Disturbance of HL-A antigen frequency psoriasis. New England Journal of Medicine, 287, 740-745

Wright, V., and Moll, J. M. H. (1973). Ankylosing spondylị. tis. British Journal of Hospital Medicine, 9, 331-341.

Woodrow, J. C., Dave, V. K., Usher, N., and Anderson, (1975). The HL-A system and psoriasis. British Journal of Dermatology, 92, 427-436. 